\title{
Percutaneous Endoscopic Gastrostomy Tube Placement in Patients with Head and Neck Cancer Treated with Radiotherapy
}

This article was published in the following Dove Press journal: Cancer Management and Research

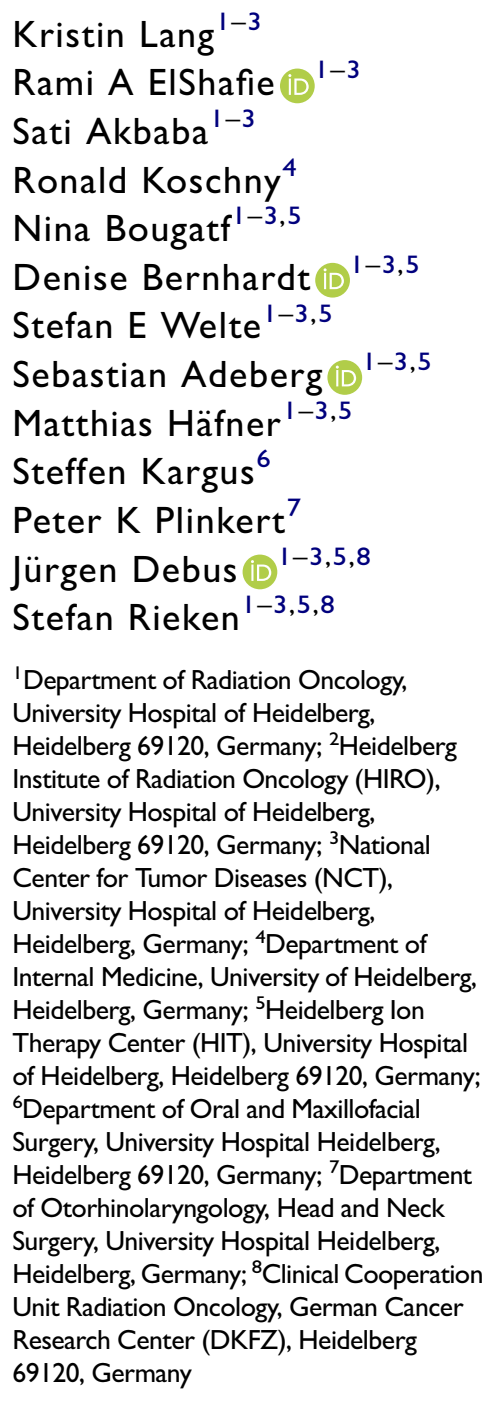

Correspondence: Kristin Lang Department of Radiation Oncology, University of Heidelberg, Im Neuenheimer Feld 400, Heidelberg 69120, Germany $\mathrm{Tel}+49-622 \mathrm{I}-56-8202$

Fax +49-622I-56-5353

Email Kristin.Lang@med.uni-heidelberg.de
Background and aim: The primary aim of our study was to evaluate percutaneous endoscopic gastrostomy (PEG) tube placement depending on body weight and body mass index in patients undergoing radiotherapy (RT) for head and neck cancer (HNC). A secondary aim was to evaluate the course of weight change following PEG placement.

Methods: We retrospectively reviewed the medical records of 186 patients with HNC undergoing radiotherapy (RT) or chemoradiotherapy (CRT) at our institution between January 2010 and August 2017. Initial weight and nutritional intake were analyzed prior to RT initiation and then followed throughout treatment until completion. Based on these data, the indication of PEG placement was determined. Medical records were also reviewed to analyze PEG-related acute toxicities.

Results: A total of 186 patients met inclusion criteria. Patients were most commonly male $(\mathrm{n}=123,66.1 \%)$ with squamous cell carcinoma $(\mathrm{n}=164,88.2 \%)$. Patients who had dysphagia prior to treatment initiation as well as patients with a BMI $<18.5 \mathrm{~kg} / \mathrm{m}^{2}$ needed PEG placement earlier during the treatment course. Low-grade toxicities related to PEG insertion were observed in $10.7 \%$ patients, with peristomal pain and redness adjacent to the PEG tube insertion site being most common. High-grade toxicities, such as peritonitis and organ injury, were found in $4.9 \%$ of patients.

Conclusion: Underweight patients and those with preexisting dysphagia should be closely screened during RT for weight loss and decreased oral intake. For weight loss greater than $4.5 \%$ during the treatment of HNC, early PEG-tube placement should be considered. Further prospective studies are needed to confirm these findings, and delineate a scoring system for timing of PEG use (prophylactic vs reactive) as well as assess the quality of life in patients with $\mathrm{HNC}$ who receive PEG placement.

Keywords: head and neck cancer, radiotherapy, PEG placement, body mass index, toxicity

\section{Introduction}

Head and neck cancer (HNC) is the sixth most common malignancy worldwide. ${ }^{1,2}$ $\mathrm{HNC}$ is most commonly of squamous differentiation and includes a variety of tumors located within the oral and nasal cavities, pharynx, lips, tongue, larynx and salivary glands. ${ }^{3,4}$ Radiotherapy (RT) or chemoradiotherapy (CRT), administered as primary or adjuvant treatment, has become an important treatment strategy over the past several decades for patients with locally advanced disease or those who are unable to undergo surgical resection. ${ }^{4-6}$ A major problem seen among patients with $\mathrm{HNC}$ is malnutrition, the prevalence of which is estimated to be around 35-60\%. Over the past few years, 
several interventions have been developed to improve the nutritional status of this cohort and to decrease weight loss in patients undergoing RT; these include dietary counseling, nutritional supplements, and the use of a percutaneous endoscopic gastrostomy (PEG) tube. ${ }^{7}$ The tumor location itself can often cause nutritional complications before treatment begins, with $5-52 \%$ of patients reporting dysphagia before undergoing CRT or $\mathrm{RT}^{8}{ }^{8}$ In addition, the side effects of RT and CRT, including esophagitis, mucositis, xerostomia, dysphagia, odynophagia, nausea, and fatigue, can contribute to poor nutritional intake in this cohort. ${ }^{9}$ PEG tube placement through a minimally invasive technique is an accepted strategy for enteral feeding, ${ }^{4,10-13}$ as demonstrated by several previous studies which showed that PEG tube placement is effective in preventing weight loss and providing sufficient nutritional intake to prevent malnutrition. This is a commonly employed technique because there is no longer a delay in treatment initiation due to the minimally invasive technique. ${ }^{12,13}$ Nevertheless, there remain different opinions regarding the timing of PEG tube use: prophylactic vs reactive placement has been discussed in a controversial manner. ${ }^{15,18}$ Furthermore, not all patients with cancer benefit from a prophylactic feeding tube. In fact, a number of studies have shown excellent results without PEG placement. ${ }^{15,18-20}$ Additionally, a lower quality of life and a higher rate of complications was observed among patients who completed RT and received a prophylactic PEG tube placement. ${ }^{14-17} \mathrm{On}$ the other hand, several studies have indicated that PEG tube placement is associated with a decrease in treatment-related weight loss. ${ }^{15,18-20}$

At our center, physicians decide before treatment whether PEG tube placement based on the presence of a number of symptoms such as dysphagia and anorexia, which could negatively affect the treatment or the patient's ability to maintain adequate nutritional intake. The primary objective of this retrospective study was to evaluate the period of time between RT initiation and PEG tube placement. The secondary endpoints were to analyze body mass index (BMI) and body weight (kilogram $(\mathrm{kg})$ ) of patients over the period of RT in an attempt to better understand any potential impact or influence on time of PEG insertion, even the impact of the planning target volume (PTV) on time when PEG tube was necessary and evaluate the PEG-insertionrelated complications. Gaining additional insight could help improve clinical decision-making regarding PEG tube placement, underscoring the rationale for our study.

\section{Patients and Methods}

\section{Study Design}

A retrospective analysis was conducted using the clinical, operative and hospital records of patients who received gastric PEG tube placement either before or during administration of RT in the Department of Radiation Oncology at the University Hospital of Heidelberg between January 2010 and August 2017. Ethical approval was obtained prior to study initiation and procedures were carried out according to national and institutional ethical standards.

\section{Study Population}

Each patient with HNC cancer who underwent PEG tube placement either before or during RT at our department was included in this study. Patients receiving either concurrent chemotherapy or immunotherapy with RT were also included. Patients who did not require PEG tube placement were excluded. The total study population consisted of 186 patients (Figure 1). All patients were given the opportunity to have a nutritional consultation at the NCT (Nationales Zentrum für Tumorerkrankungen) Heidelberg, but these data are not characterized in the present work given a lack of documentation. Each patient was referred through social services to a nursing service at the end of treatment, which provided home care instructions regarding utilization of the PEG tube.

We evaluated patients' demographic characteristics, tumor location in head and neck, tumor stage (TNM), reason for PEG tube placement and complications related to PEG tube placement.

Regarding patient's nutritional status, the BMI [weight $(\mathrm{kg}) /$ height squared $\left(\mathrm{m}^{2}\right)$ ] and body weight in kilogram (kg) were analyzed at three different times: a) at the start of RT, b) at the day of PEG tube placement and c) at the end of therapy. For statistical analysis we categorized all patients into the following three groups based on their initial BMI score $\left(\mathrm{kg} / \mathrm{m}^{2}\right)$ :

$$
\begin{aligned}
& \text { group 1: }<18.5 \mathrm{~kg} / \mathrm{m}^{2} \\
& \text { group 2: } 18.5-24.9 \mathrm{~kg} / \mathrm{m}^{2} \\
& \text { group 3: } \geq 25.0 \mathrm{~kg} / \mathrm{m}^{2}
\end{aligned}
$$

\section{Patient Characteristics}

A total of 186 patients met inclusion criteria, with 123 patients (66.1\%) being male and 63 patients $(33.9 \%)$ female. Histologically, 164 patients (88.2\%) had squamous cell carcinoma, 2 patients $(1.1 \%)$ had adenocarcinoma, 6 patients (3.2\%) had adenoid cystic carcinoma and 14 patients (3.2\%) had other histologies. In terms of staging, $68.8 \%$ had locally 


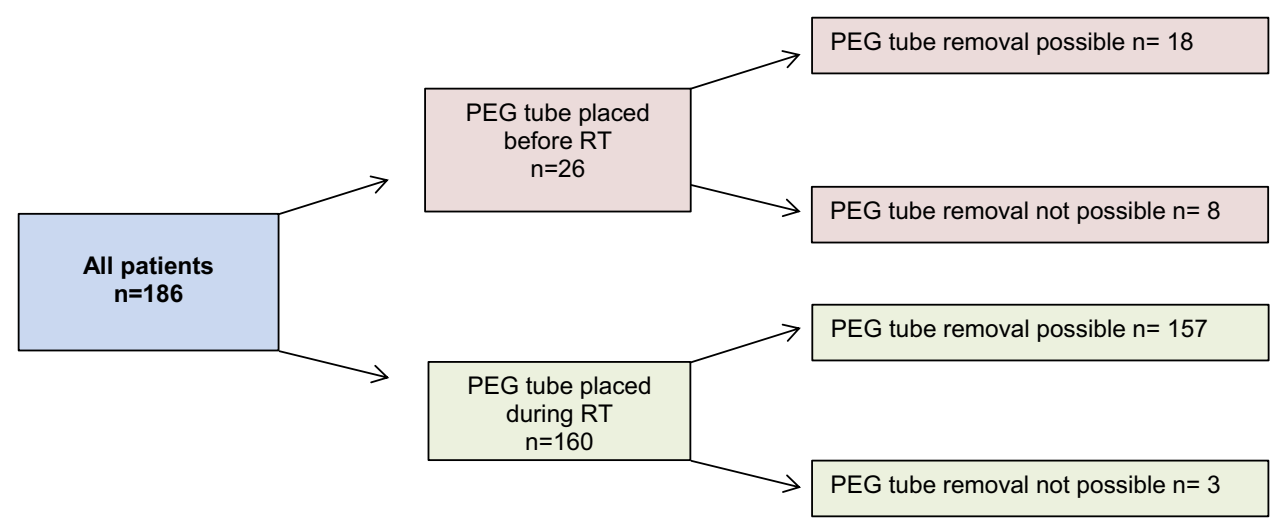

Figure I Schematic representation of patient subgroups in the present study. Abbreviations: RT, radiotherapy; PEG, percutaneous endoscopic gastrostomy.

advanced disease (T3-4) and 76.9\% were node-positive $(\mathrm{N}+)$. Four patients $(2.2 \%)$ presented with distant metastases. Detailed patient and tumor characteristics are shown in Table 1.

\section{Nutritional Status}

The development of body weight and BMI for patients who received PEG insertion during RT is shown in Figure 2. Median time to PEG insertion in group 1 was 15 days, group 218 days and in group 3, 26 days. Table 3 shows changes in body weight and BMI in patients who received PEG insertion before RT. Weight loss is expressed as a percentage decrease from baseline and is displayed in association with the median number of days until PEG was placed during RT. Table 2 illustrates weight loss from time of RT initiation to PEG tube placment for the entire cohort. Figure 2 illustrates weight loss according to the three BMI groups as well as the elapsed days until PEG tube placement.

\section{Data Collection and Treatment Toxicity}

Patient records were reviewed to collect nutritional status information prior to radiation treatment, during treatment, and after treatment completion. Beyond general demographic characteristics, body weight, BMI, oral intake and patient-reported dysphagia and treatment-related toxicities were specifically examined.

Acute treatment-related toxicity was evaluated according to the Common Terminology Criteria for Adverse Events (CTCAE) criteria (version 4.03, US Department of Health and Human Services, Washington, DC, USA). Symptoms of grades 1 and 2 according to CTCAE were referred to as low-grade and grades 3 and 4 as high-grade toxicities. All patients were seen by a doctor once a week to detect side effects. Adverse events which led to PEG- insertion (RT related complications) like mucositis, dysphagia and esophageal stenosis were monitored. Following PEG-tube placement, patients were required to recover in the hospital. Therefore, the medical record was reviewed to analyze PEG-related toxicity, including skin toxicity (redness, dryness, pus), pain, infection, or anemia.

\section{Statistical Analysis}

Statistical analysis was conducted using IBM SPSS software version 24. The results are presented as mean and percentage. PEG-free interval (PFI) for the whole cohort, for patients with lower BMI $\left(<18.5 \mathrm{~kg} / \mathrm{m}^{2}\right)$, preexisting dysphagia and higher treated RT doses (total doses $\geq 66 \mathrm{~Gy}$ ) was calculated by Kaplan-Meier estimates. The observed time was defined as the time from treatment initiation to PEG-insertion.

Univariate analysis was conducted using logistic regression analysis. As this is a retrospective analysis, $p$-values are of a descriptive nature. A descriptive $p$-value $\leq 0.05$ was considered statistically significant. Variables that were tested for significance were selected for a multivariate logistic regression model. Variables that were not significant in univariate analysis, but were deemed to have clinical significance based on literature were also included in the multivariate model (BMI groups and body weight). Subgroups were compared using the log rank test. Odds ratios were accompanied with 95\% confidence intervals. For comparison between groups, the chisquared and Student's t-tests were performed for categorical and continuous variables, respectively.

\section{Ethics}

This study was performed following institutional guidelines and the Declaration of Helsinki of 1975 in its most recent version. Ethical approval for the study was given from the local ethics committee at University Hospital Heidelberg. 
Table I Patient Characteristics

\begin{tabular}{|c|c|c|}
\hline \multirow[t]{2}{*}{ Characteristics } & \multicolumn{2}{|c|}{ All Patients } \\
\hline & $\mathbf{n}$ & $\%$ \\
\hline No. of patients & 186 & 100 \\
\hline \multicolumn{3}{|l|}{ Age at PEG placement } \\
\hline Median (years) & 67 & \\
\hline Range (years) & $21-88$ & \\
\hline \multicolumn{3}{|l|}{ Sex } \\
\hline Male & 123 & 66.1 \\
\hline Female & 63 & 33.9 \\
\hline \multicolumn{3}{|l|}{ Histology } \\
\hline SCC & 164 & 88.2 \\
\hline Adenocarcinoma & 2 & 1.1 \\
\hline Adenoid cystic carcinoma (ACC) & 6 & 3.2 \\
\hline Others & 14 & 7.5 \\
\hline \multicolumn{3}{|l|}{ Primary tumor locations } \\
\hline Oral cavity & 71 & 38.2 \\
\hline Hypopharynx & 30 & 16.1 \\
\hline Glottis region & 20 & 10.8 \\
\hline Oropharynx & 15 & 8.1 \\
\hline Larynx & 12 & 6.5 \\
\hline Paranasal sinus & 4 & 2.2 \\
\hline Nasopharynx & 4 & 2.2 \\
\hline Thyroid gland & 2 & I.I \\
\hline Lung & I & 0.54 \\
\hline Carcinoma of unknown primary (CUP) & 6 & 3.2 \\
\hline \multicolumn{3}{|l|}{ TNM stage } \\
\hline TI & 15 & 8.1 \\
\hline $\mathrm{T} 2$ & 37 & 19.9 \\
\hline T3 & 55 & 29.6 \\
\hline $\mathrm{T} 4$ & 73 & 39.2 \\
\hline Tx & 6 & 3.2 \\
\hline No & 43 & 23.1 \\
\hline $\mathrm{N}+$ & 143 & 76.9 \\
\hline Mo & 153 & 82.3 \\
\hline MI & 4 & 2.2 \\
\hline Mx & 29 & 15.5 \\
\hline
\end{tabular}

Table 2 Weight Loss from Time of RT Initiation to PEG Tube Placement for the Entire Cohort

\begin{tabular}{|l|l|}
\hline Weight Loss (\%) & n (\%) \\
\hline$\leq 0 \%$ & $47(25.3)$ \\
$\leq 5 \%$ & $69(37.1)$ \\
$>5-10 \%$ & $42(22.6)$ \\
$>10 \%$ & $14(7.5)$ \\
\hline
\end{tabular}

As the data were analyzed retrospectively and anonymously and treatment of patients was not affected by this study, no written informed consent from each individual patient was necessary according to institutional standards and the local ethics committee decision.

\section{Results RT Planning Characteristics}

For planning purposes, a computed tomography (CT) with a maximum slice thickness of $3 \mathrm{~mm}$ was performed for each patient. Contrast-enhanced images were obtained when not clinically contra-indicated. Individual head fixation including neck and shoulders was achieved by the use of a thermoplastic mask fitted for each patient. Target volume definition was defined according to ICRU guidelines. Total dose was prescribed with regard to tumor location, staging and treatment intent, whether curative or palliative. RT was administered to 149 patients $(80.1 \%)$ as primary treatment and to 37 patients $(19.9 \%)$ in adjuvantly following surgical resection. In total, $74.7 \%(n=139)$ of patients received concomitant systemic therapy: $55.9 \%(\mathrm{n}=104)$ received chemotherapy and $18.8 \%(n=35)$ received immunotherapy. Patients were treated with either three-dimensional conformal RT (3D-CRT) $(n=3,1.6 \%)$, intensity-modulated RT (IMRT) $\left(\mathrm{n}=162,87.1 \%\right.$, VMAT $53.1 \%$, TomoTherapy ${ }^{\circledR}$ $34 \%$ ), combined therapy with IMRT and carbon-ions (C12) $(\mathrm{n}=17,9.1 \%)$ or protons alone $(\mathrm{n}=3,1.6 \%)$. Radiation was delivered in two phases: a primary phase encompassing all sites of disease and respective clinical margins and a boost phase encompassing gross disease with a small clinical margin. The median primary phase dose was 56Gy (range, 23$72 \mathrm{~Gy}$ ), administered using a median of $1.8 \mathrm{~Gy} /$ fraction (range, 1.8-3.0Gy/fraction). The boost was given either simultaneously or after completing the primary phase, with a median dose of $2.2 \mathrm{~Gy} /$ fraction (range, $1.0-3.3 \mathrm{~Gy} /$ fraction) to a median total dose of 70Gy (range, 48-82Gy). Treatment was most commonly delivered in five fractions per week for photon treatment and 5-6 fractions per week for particle therapy. A total of 183 patients $(98.4 \%)$ completed RT as planned; 3 patients aborted treatment because of a fulminant gastrointestinal infection unrelated to treatment. The median PTV during the primary course was $771 \mathrm{~mL}$ (range, 51$1843 \mathrm{~mL}$ ), and $158 \mathrm{~mL}$ (range, $1.0-3.3 \mathrm{~mL}$ ) during the boostphase. Detailed treatment characteristics are shown in Table 4.

\section{Clinical Factors Affecting Timing of PEG-Placement}

The median age at the time of PEG tube placement was 67 years (range, 21-88years). The indication for the 26 patients 


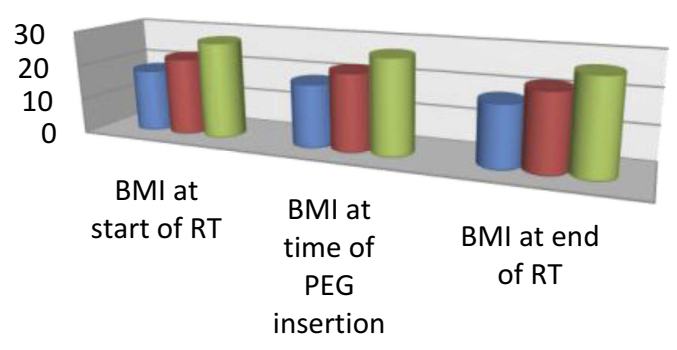

\begin{tabular}{|c|c|c|c|}
\cline { 2 - 4 } \multicolumn{1}{c|}{} & BMI at start of RT & $\begin{array}{c}\text { BMI at time of PEG } \\
\text { insertion }\end{array}$ & BMI at end of RT \\
\hline$\square$ Group 1 & 17.9 & 18 & 17.4 \\
\hline$\square$ Group 2 & 22.2 & 22 & 21.6 \\
\hline$\square$ Group 3 & 27.6 & 27 & 26.4 \\
\hline
\end{tabular}

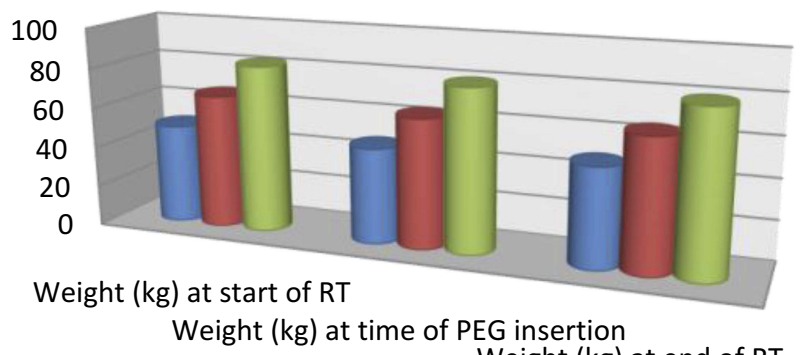

Weight $(\mathrm{kg})$ at end of RT

\begin{tabular}{|l|c|c|c|}
\cline { 2 - 4 } \multicolumn{1}{c|}{} & $\begin{array}{c}\text { Weight (kg) at start of } \\
\text { RT }\end{array}$ & $\begin{array}{c}\text { Weight (kg) at time of } \\
\text { PEG insertion }\end{array}$ & $\begin{array}{c}\text { Weight (kg) at end of } \\
\text { RT }\end{array}$ \\
\hline$\square$ Group 1 & 49.5 & 47.5 & 49 \\
\hline$\square$ Group 2 & 66.5 & 64 & 65 \\
\hline$\square$ Group 3 & 83 & 80.5 & 80 \\
\hline
\end{tabular}

\begin{tabular}{|l|l|}
\hline & $\begin{array}{l}\text { Median time until PEG } \\
\text { tube placement }\end{array}$ \\
\hline Group 1 & 15 days \\
\hline Group 2 & 18 days \\
\hline Group 3 & 26 days \\
\hline
\end{tabular}

Figure $2 \mathrm{BMI}$ and body weight development according to group among the 160 patients who received PEG placement prior to RT or at the end of RT. BMI and weight development in the three groups: before RT (Group I BMI/weight range 12.4-18.4/33kg-63kg; Group 2 BMI/weight range 12-18/33kg-63kg; Group 3 BMI/weight range 12.6-20.1/34kg-64kg), at time of PEG insertion (Group I BMI/weight range 18.5-25.0/48 kg-85kg; Group 2 BMl/weight range I8-25/45 kg-84kg; Group 3 BMI/weight range $16.4-25.6 / 47 \mathrm{~kg}-8 \mathrm{l} \mathrm{kg}$ ) and after completion of RT (Group I BMI/weight range 25-36.8/64kg-II2kg; Group 2 BMI/weight range 25-37/58kg-; I05kg; Group 3 BMI/weight range $20.9-34.0 / 59 \mathrm{~kg}-110 \mathrm{~kg}$ ). Right table shows Synopsis of the three groups for median time of PEG insertion after treatment start.

who received PEG insertion before RT treatment was pronounced dysphagia and resulting weight loss. The median age at the time of PEG tube placement was 67 years (range, 21-88years). The indication for the 26 patients who received PEG insertion before RT treatment was pronounced dysphagia and resulting weight loss. Forty-seven patients $(25.3 \%)$ had problems with progressive dysphagia during RT in which pain prevented adequate oral intake, necessitating PEG tube placement. After PEG insertion eight patients of these 47 had a stable weight $( \pm 0 \mathrm{~kg})$ at the end of RT; the remaining patients lost between one to six kilograms until the end of RT: $-1 \mathrm{~kg}$ in 10 patients, $-2 \mathrm{~kg}$ in 7 patients, $-3 \mathrm{~kg}$ in 3 patients, $-1 \mathrm{~kg}$ in 1 patient, $-5 \mathrm{~kg}$ in 3 patients, $-6 \mathrm{~kg}$ in 3 patients. The other eleven patients retained their body weight (within 1 to $5 \mathrm{~kg}$ ) after PEG insertion until treatment completion.

Table $3 \mathrm{BMI}$ and Body Weight (Ranges) Development by Group Among the 26 Patients Who Received PEG Placement During RT

\begin{tabular}{|l|l|l|l|l|}
\hline & Weight Initial (kg) & BMI Initial & Weight (kg) End of Treatment & BMI End of Treatment \\
\hline Group I & $57(43-63)$ & $18.1(13.8-18.4)$ & $54(47-64)$ & $17.9(15.2-20.1)$ \\
Group 2 & $67(53-77)$ & $21.8(19.8-24.9)$ & $67(51-76)$ & $21.8(19.4-24.2)$ \\
Group 3 & $83.5(67-106)$ & $27.8(25.6-35.0)$ & $83.5(67-99)$ & $27.6(27.8-32.7)$ \\
\hline
\end{tabular}


Table 4 Treatment Characteristics

\begin{tabular}{|c|c|c|}
\hline \multirow[t]{2}{*}{ Characteristics } & \multicolumn{2}{|c|}{ All Patients } \\
\hline & $\mathbf{n}$ & $\%$ \\
\hline No. of patients & 186 & 00 \\
\hline \multicolumn{3}{|l|}{ RT setting } \\
\hline Definitive & 149 & 80.1 \\
\hline Adjuvant & 37 & 19.9 \\
\hline \multicolumn{3}{|l|}{ RT-technique } \\
\hline IMRT & 163 & 87.6 \\
\hline 3D-CRT & 3 & 1.6 \\
\hline IMRT + Carbon-lons & 17 & 9.1 \\
\hline Protons & 3 & 1.6 \\
\hline \multicolumn{3}{|l|}{ Concomitant therapy } \\
\hline Chemotherapy & 98 & 52.7 \\
\hline Immunotherapy & 32 & 47.3 \\
\hline \multicolumn{3}{|l|}{ Neck irradiation } \\
\hline Ipsilateral neck & 57 & 30.6 \\
\hline Bilateral neck & 102 & 54.8 \\
\hline \multicolumn{3}{|l|}{ Radiotherapy dose (Gy) } \\
\hline \multicolumn{3}{|l|}{ Main course } \\
\hline median cumulative dose (range) & \multicolumn{2}{|c|}{$56.0(48.0-72)$} \\
\hline median dose per fraction (range) & \multicolumn{2}{|c|}{$1.8(1.8-3.0)$} \\
\hline \multicolumn{3}{|l|}{ Boost } \\
\hline median cumulative dose (range) & \multicolumn{2}{|c|}{$70.0(48-92)$} \\
\hline median dose per fraction (range) & \multicolumn{2}{|c|}{$2.1(2.1-3.0)$} \\
\hline \multicolumn{3}{|l|}{ PTV (mL) } \\
\hline \multicolumn{3}{|l|}{ Main course } \\
\hline Median & \multicolumn{2}{|c|}{771} \\
\hline Range & \multicolumn{2}{|c|}{$51-1843$} \\
\hline QI-Q3 & \multicolumn{2}{|c|}{$595-1007$} \\
\hline \multicolumn{3}{|l|}{ Boost } \\
\hline Median & \multicolumn{2}{|c|}{158} \\
\hline Range & \multicolumn{2}{|c|}{$26-1359$} \\
\hline QI-Q3 & \multicolumn{2}{|c|}{$108-265$} \\
\hline
\end{tabular}

From the cohort as a whole, 69 patients (37.1\%) gained between $1 \%$ and $<5 \%$ in body weight, 42 patients $(22.6 \%)$ gained between $5 \%$ and $10 \%$ in body weight, and 14 patients (7.5\%) lost $>10 \%$ of their initial body weight. In comparing the cohort based on PEG placement either before or during treatment, there was no significant difference in median loss of body weight among the two groups.

The median time to PEG-placement in patients with preexisting dysphagia was 6 days, whereas time to PEGplacement was 23 days among patients without preexisting dysphagia.

\section{Univariable and Multivariable Analyses}

Univariable and multivariable Cox regression models were used to examine the effect of radiotherapy on earlier PEGplacement time for all BMI groups. Kaplan Meier estimates for the cohort showed a median PEG-free-interval (PFI) from the start of RT to PEG insertion of 20.5 days. Severely underweight patients $\left(<18.5 \mathrm{~kg} / \mathrm{m}^{2}\right)$ were found to have a significantly earlier time to $P E G$ insertion than normal or overweight patients $(\mathrm{p}=0.030)$. Similarly, patients with dysphagia before treatment $(\mathrm{p}<0.001)$ as well as those requiring RT doses $>66 \mathrm{~Gy}(\mathrm{p}=0.021)$ were found to have significantly earlier PEG insertion. Results of univariable and multivariable cox regression models are summarized in Table 5 and Figure 3.

\section{RT-Related Toxicity}

Forty-seven patients (25.3\%) reported dysphagia before treatment initiation: grade 1 and 2 (low-grade) in 36 patients (76.6\%) and grade 3 and 4 (high-grade) in 11 patients (5.9\%).

The most common acute RT-related complication that led to PEG insertion was mucositis (83 patients (44.4\%): low grade in 21 patients $(11.2 \%)$ and high grade in 62 patients (33.2\%)). RT-related toxicity including dysphagia and esophagitis was detected in 100 patients $(53.5 \%)$, low grade in 46 patients $(24.6 \%)$ and high grade in 54 patients $(28.9 \%)$. During RT, three patients $(1.6 \%)$ developed esophageal stenosis.

\section{PEG-Related Toxicity}

A total of 160 patients (69\%) underwent endoscopic PEG tube placement, while the remaining 26 patients (14\%) underwent surgical intervention for placement. Acute toxicities associated with minor complications after PEG tube placement were detected in 20 patients $(10.7 \%)$ and included tube dislodgement, tube clogging, wound infection, and peri-

Table 5 Univariable and Multivariable Cox Regression Models for Earlier PEG Insertion Time

\begin{tabular}{|l|l|l|}
\hline Parameter & p value & Cl $95 \%$ \\
\hline Age $<60$ years vs $\geq 60$ years & 0.578 & $0.797-1.502$ \\
Gender male vs female & 0.591 & $0.673-1.253$ \\
BMI group I vs group $2 / 3$ & 0.030 & $1.098-6.21 \mathrm{I}$ \\
$\mathrm{T}$ stage $\mathrm{TI} / 2$ vs T3/4 & 0.110 & $0.567-1.060$ \\
$\mathrm{~N}$ stage N0 vs N+ & $0.46 \mathrm{I}$ & $0.624-1.239$ \\
Dysphagia symptoms at diagnosis CTCAE & $<0.00 \mathrm{I}$ & $4.515-9.858$ \\
grade $\geq 3$ & & \\
Concomitant therapy & 0.273 & $0.863-1.685$ \\
Cumulative RT-dose $<60 G y$ vs $\geq 60 G y$ & 0.021 & $0.514-0.948$ \\
PTV size $<800 \mathrm{~mL}$ vs $\geq 800 \mathrm{~mL}$ & 0.480 & $0.830-1.484$ \\
\hline
\end{tabular}




\section{A}
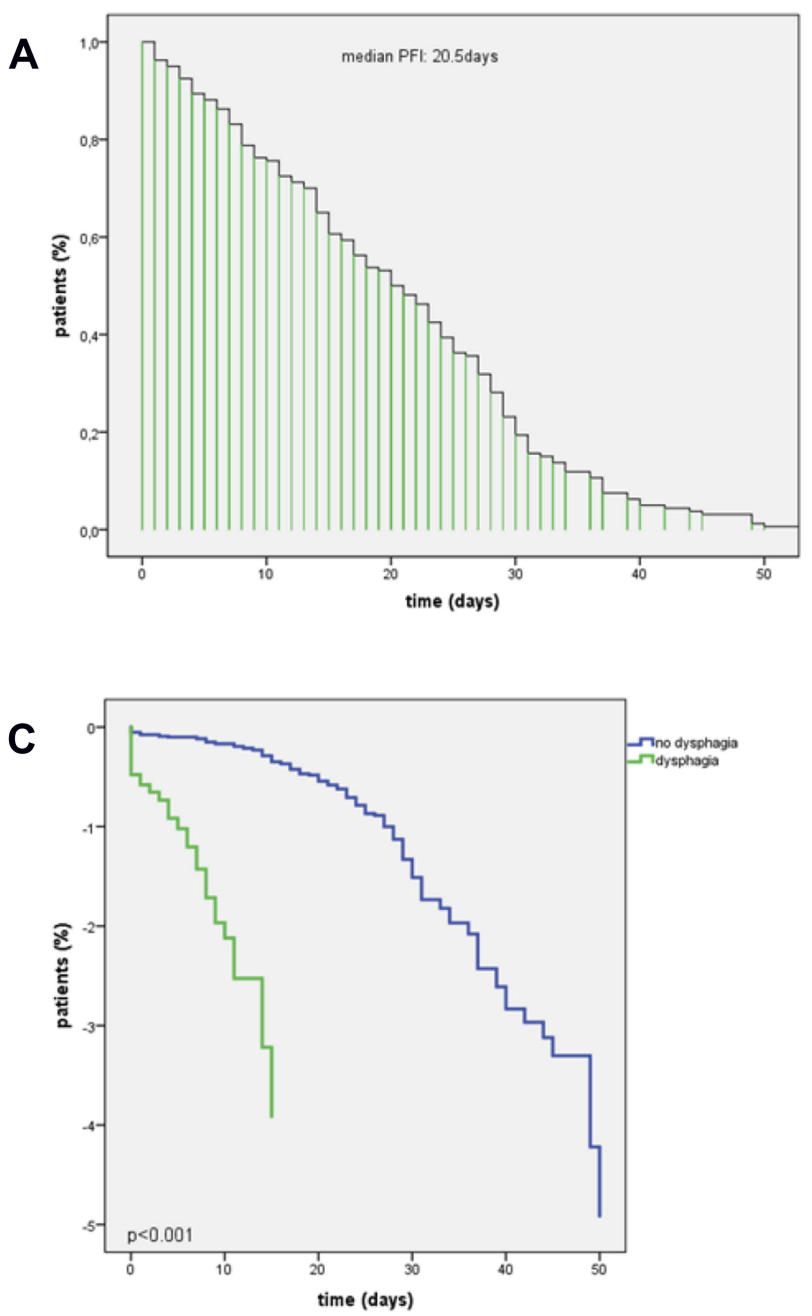

B

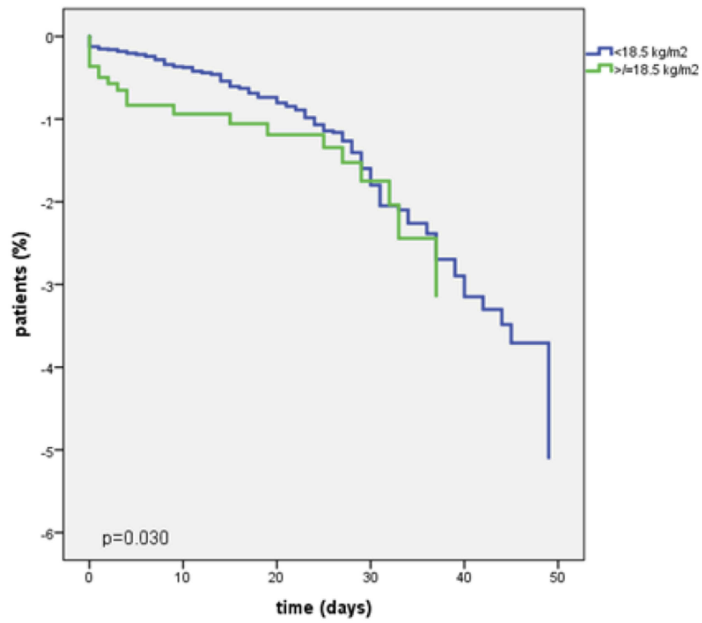

D

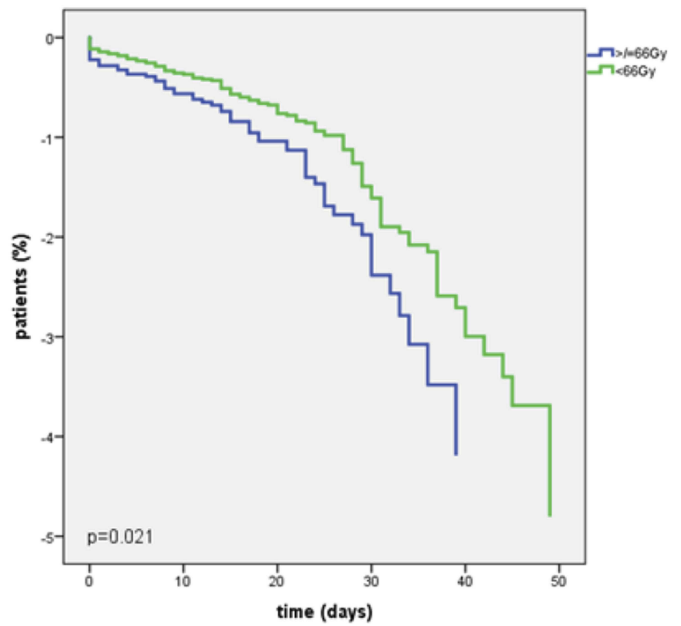

Figure 3 Kaplan-Meier estimates for PEG-free interval (PFI). (A) median time for all patients to PEG placement was 20.5 days (B) significantly earlier time of PEG insertion in patients with $\mathrm{BMI}<18.5 \mathrm{~kg} / \mathrm{m}^{2}$ ( $\left.\mathrm{P}=0.030, \mathrm{Cl} \mathrm{I} .098-6.2 \mathrm{II}\right)$; (C) significantly earlier time of PEG insertion in patients with dysphagia CTCAE $\geq$ grade 3 at baseline ( $<<0.00 \mathrm{I}$, Cl 4.5I5-9.858); (D) significantly earlier time of PEG insertion in patients with requiring cumulative RT-doses $\geq 66 \mathrm{~Gy}(\mathrm{P}=0.02 \mathrm{I}, \mathrm{Cl} 0.5 \mathrm{I} 4-0.984)$.

Abbreviations: PEG, percutaneous endoscopic gastrostomy; PFI, PEG-free interval.

stomal wound leakage. Eight patients (4.3\%) developed high-grade complications with laparotomy, including peritonitis in five patients $(2.7 \%)$ and organ perforation (intestinal) in three patients $(1.6 \%)$.

In follow-up, the median duration of the PEG tube remaining in-situ was 8.7 months (range, 3.2-13.7 months). As a result of pharyngeal stenosis in follow-up examinations, PEG tube removal was not possible in 11 patients (5.9\%). Of these, 8 patients had preexisting dysphagia, while 3 patients developed dysphagia during RT (Figure 1).

\section{Discussion}

RT or CRT for head-and-neck cancers can cause severe mucositis, intolerable pain, swallowing dysfunction, and dysphagia, often resulting in significant malnutrition.
Consequence of these complications include weight loss due to reduced food intake. The European Society for Clinical Nutrition and Metabolism (ESPEN) guidelines have identified that malnutrition during the treatment of cancers decreases the quality and activity of daily life, increases side effects, and decreases response to treatment interventions. $^{28,33}$ PEG tubes have been used to provide nutritional support and decrease the incidence of malnutrition during RT. ${ }^{12,21-26,28}$

This retrospective study demonstrated that patients with an initial low BMI $\left(<18.5 \mathrm{~kg} / \mathrm{m}^{2}\right)$ and patients with preexisting tumor-associated dysphagia were significantly more likely to receive earlier PEG placement. In total, $25.3 \%$ of patients developed dysphagia before the start of RT and underwent earlier PEG tube placement (after 6.0 days of 
RT), when compared to patients not reporting this symptom. RT-related toxicities including dysphagia and esophagitis were detected in 100 patients (53.5\%). Worldwide, some centers avoid PEG tube placement unless patients show signs of weight loss or swallowing disability, while other centers prophylactically place them before treatment initiation. There are no internationally accepted standard methods for assessing the nutritional status of oncologic patients to assess the value of a prophylactic PEG tube use. ${ }^{12,21-26,30}$

In 1999, Morrison and Hark published a grading system for weight loss within the first week, describing weight loss of $1-2 \%$ as significant and $>2 \%$ weight loss as a severe side effect of therapy. A weight loss of $>5 \%$ from baseline in the first month after the start of therapy could lead to severe consequences. ${ }^{27}$ Weight loss is a nutritional indicator that reflects reduced intake or nutritional discrepancy. Indeed, the indication among the 26 patients who received PEG insertion prior to treatment initiation was pronounced dysphagia resulting in weight loss. In the present study, the results of our analysis on timing of PEG tube placement showed that obese patients had a median weight loss of $2.5 \%$ and received a PEG tube within 26 days. Those patients who were underweight with BMIs $<18.5 \mathrm{~kg} / \mathrm{m}^{2}$ had a median weight loss of $2.0 \%$, followed by PEG tube placement after a median of 15 days. Based on the published data by Morrison and Hark, ${ }^{27}$ patients in our study collectively underwent PEG tube placement when there was a significant weight loss (1-2\%). These results imply that patients with HNC are generally identified as a group that may require assistance through caloric supplementation via PEG placement. The literature lacks studies correlating target volume size (PTV) with the timing of PEG tube placement. The idea that a larger PTV leads to earlier PEG tube placement was not confirmed in our analysis $(\mathrm{p}=0.480)$. Similar to our data, Takahasi et al showed that PEG tube placement constituted a practicable nutritional intervention with quite a few benefits, such as effective reduction of treatment-related weight loss with stable weight at the end of RT: median weight at PEG tube placement was 67.4 vs $67.3 \mathrm{~kg}$ at the end of RT. ${ }^{34}$ These data underscore the importance of monitoring the nutritional status of $\mathrm{HNC}$ patients, indicating that timing is important as well.

Several previous studies in the literature have described that PEG tube insertion is a well-tolerated procedure with minimal morbidity and mortality, allowing a good nutritional support in patients who are unable to safely tolerate oral intake. ${ }^{29-31}$ The literature reports that about $13-40 \%$ of patients receiving PEG tube placement experience minor complications such as maceration due to leakage of gastric contents around the tube and peristomal pain. ${ }^{30,31}$ Serious complications requiring further intervention have been reported in $0.4-4.4 \%$ of the procedures and include peristomal leakage with peritonitis, necrotizing fasciitis of the anterior abdominal wall, gastric bleeding, injury to internal organs, tumor seeding at the PEG site, and death. ${ }^{29-31}$ These results are comparable with our findings, with low-grade toxicity found in $10.7 \%$ of patients, due to peristomal pain and erythema adjacent to the PEG tube insertion site, and high-grade toxicity observed in $4.9 \%$ of patients due to peritonitis and organ injury.

Despite the improvement in maintaining nutritional intake, the literature also reports several negative aspects of PEG tube placement when performed as a prophylactic measure, such as more severe and long-standing dysphagia caused by muscle disuse and atrophy as well as PEGassociated complications. ${ }^{32}$ These findings are similar to those presented in the present study, wherein we observed that PEG tube removal was not possible in 11 patients because of severe dysphagia caused by pharyngeal fibrosis/stenosis. Of these, 8 patients had preexisting dysphagia and needed PEG insertion before the start of RT, while 3 patients developed dysphagia during RT and needed the PEG insertion later. Therefore, the early identification of patients who could benefit from PEG tube insertion is a critical aspect that should be routinely considered.

Limitations of this study include its retrospective nature and the lack of subjective data to measure patient quality of life. Selection bias could also be at play, because receiving a PEG tube was based on the clinical decision making and subject to the patient's consent; compliant and better informed patients would be more prone to receiving PEG tube placement, which could have affected the results of this study. Therefore, a prospective follow-up study is needed to confirm the findings presented herein. Additionally, prospective studies could be used to develop a prognostic scoring system for patients with $\mathrm{HNC}$ based on the results obtained in the present analysis.

\section{Conclusion}

Patients with preexisting dysphagia or who are initially underweight should be closely screened during RT for weight loss and oral intake. For a weight loss of more than $4.5 \%$ during the HNC treatment, early PEGplacement should be considered in an attempt to maintain 
adequate nutrition to improve treatment tolerance and reducing side effects. Further prospective studies could be used to delineate a scoring system for prophylactic vs reactive PEG placement and assess the quality of life in patients with $\mathrm{HNC}$ receiving PEG placement.

\section{Abbreviations}

$\mathrm{HNC}$, head and neck cancer; SCC, squamous cell carcinoma; CIRT, carbon ion radiotherapy; RT, radiotherapy; PEG, percutaneous endoscopic gastrostomy; CRT, chemoradiotherapy; BMI, body mass index; TNM, Tumor Node Metastasis; UICC, International Union against Cancer; WHO, World Health Organization; CTCAE, Common Terminology Criteria for Adverse Events; PTV, planning target volume; CT, chemotherapy; IT, immunotherapy.

\section{Ethical Considerations}

The final protocol was approved by the ethics committee of the University of Heidelberg, Heidelberg, Germany (S-421/2015).

\section{Funding}

The study was financed by the Department of Radiation Oncology of the University Hospital Heidelberg. There was no external funding source. We acknowledge financial support by Deutsche Forschungsgemeinschaft within the funding programme Open Access Publishing, by the Baden-Württemberg Ministry of Science, Research and the Arts and by Ruprecht-Karls-Universität Heidelberg.

\section{Disclosure}

Dr Sebastian Adeberg report personal fees from Merck Serono $\mathrm{GmbH}$, other from Novocure, personal fees from Accuray International Sarl, outside the submitted work. Prof. Dr. Jürgen Debus report grants from Merck Serono, grants from Accuray, grants, non-financial support from Siemens Healthineers, non-financial support from Research Labs, outside the submitted work. The authors report no other conflict of interest in this work.

\section{References}

1. Patterson JM, Brady GC, Roe JW. Research into the prevention and rehabilitation of dysphagia in head and neck cancer: a UK perspective. Curr Opin Otolaryngol Head Neck Surg. 2016;24(3):208-214. doi:10.1097/MOO.0000000000000260

2. Ferlay J, Soerjomataram I, Dikshit R, et al. Cancer incidence and mortality worldwide: sources, methods and major patterns in GLOBOCAN 2012. Int J Cancer. 2015;136(5):E359-E386. doi:10.1002/ijc.29210
3. Devlin J, Sherman E. Combined modality treatment of squamous cell cancer of the head and neck. Clin Adv Hematol Oncol. 2005;3 (5):373-382.

4. Moleiro J, Faias S, Fidalgo C, et al. Usefulness of prophylactic percutaneous gastrostomy placement in patients with head and neck cancer treated with chemoradiotherapy. Dysphagia. 2016;31 (1):84-89. doi:10.1007/s00455-015-9661-y

5. Chan AT, Gregoire V, Lefebvre J-L, et al. Nasopharyngeal cancer: EHNS-ESMO-ESTRO Clinical Practice Guidelines for diagnosis, treatment and follow-up. Ann Oncol. 2010;21(Suppl Supplement 5): v187-v189. doi:10.1093/annonc/mdq186

6. Chan AT, Gregoire V, Lefebvre J-L, et al. Nasopharyngeal cancer: EHNS-ESMO-ESTRO Clinical Practice Guidelines for diagnosis, treatment and follow-up. Ann Oncol. 2012;23(Suppl 7):vii83-vii85. doi:10.1093/annonc/mds266

7. Takenaka Y, Yamamoto M, Nakahara S, et al. Factors associated with malnutrition in patients with head and neck cancer. Acta Otolaryngol. 2014;134(10):1079-1085. doi:10.3109/00016489. 2014.906750

8. Platteaux N, Dirix P, Dejaeger E, et al. Dysphagia in head and neck cancer patients treated with chemoradiotherapy. Dysphagia. 2010;25 (2):139-152. doi:10.1007/s00455-009-9247-7

9. Marcy P-Y, Magné N, Bensadoun R-J, et al. Systematic percutaneous fluoroscopic gastrostomy for concomitant radiochemotherapy of advanced head and neck cancer: optimization of therapy. Support Care Cancer. 2000;8(5):410-413. doi:10.1007/s005200050010

10. Bossola M. Nutritional interventions in head and neck cancer patients undergoing chemoradiotherapy: a narrative review. Nutrients. 2015;7 (1):265-276. doi:10.3390/nu7010265

11. Silander E, Nyman J, Bove M, et al. Impact of prophylactic percutaneous endoscopic gastrostomy on malnutrition and quality of life in patients with head and neck cancer: a randomized study. Head Neck. 2012;34(1):1-9. doi:10.1002/hed.v34.1

12. Raykher A, Correa L, Russo L, et al. The role of pretreatment percutaneous endoscopic gastrostomy in facilitating therapy of head and neck cancer and optimizing the body mass index of the obese patient. JPEN J Parenter Enteral Nutr. 2009;33(4):404-410. doi:10.1177/0148607108327525

13. Bradley PT, Brown T, Paleri V. Gastrostomy in head and neck cancer: current literature, controversies and research. Curr Opin Otolaryngol Head Neck Surg. 2015;23(2):162-170. doi:10.1097/MOO.00000000 00000135

14. Baschnagel A, Yadav S, Marina O, et al. Toxicities and costs of placing prophylactic and reactive percutaneous gastrostomy tubes in patients with locally advanced head and neck cancers treated with chemoradiotherapy. Head Neck. 2013;36(8):1155-1161. doi:10.1002/pro.v36.8

15. Madhoun MF, Blankenship MM, Blankenship DM, et al. Prophylactic PEG placement in head and neck cancer: how many feeding tubes are unused (and unnecessary)? World J Gastroenterol. 2011;17(8):1004-1008. doi:10.3748/wjg.v17.i8.1004

16. Williams GF, Teo MT, Sen M, Dyker KE, Coyle C, Prestwich RJ. Enteral feeding outcomes after chemoradiotherapy for oropharynx cancer: a role for a prophylactic gastrostomy? Oral Oncol. 2003;48:434-440. doi:10.1016/j.oraloncology.2011.11.022

17. Clavel S, Fortin B, Després P, et al. Enteral feeding during chemoradiotherapy for advanced head-and-neck cancer: a single-institution experience using a reactive approach. Int J Radiat Oncol Biol Phys. 2011;79:763-769. doi:10.1016/j.ijrobp.2009.12.032

18. Kramer S, Newcomb M, Hessler J, et al. Prophylactic versus reactive PEG tube placement in head and neck cancer. Otolaryngol Head Neck Surg. 2014;150(3):407-412. doi:10.1177/ 0194599813517081

19. Hutcheson KA, Barringer DA, Rosenthal DI, et al. Swallowing outcomes after radiotherapy for laryngeal carcinoma. Arch Otolaryngol Head Neck Surg. 2008;134(2):178-183. doi:10.1001/ archoto. 2007.33 
20. Raynor EM, Williams MF, Martindale RG, et al. Timing of percutaneous endoscopic gastrostomy tube placement in head and neck cancer patients. Otolaryngol Head Neck Surg. 1999;120(4):479-482. doi:10.1053/ hn.1999.v120.a91408

21. Rustom IK, Jebreel A, Tayyab M, et al. Percutaneous endoscopic, radiological and surgical gastrostomy tubes: a comparison study in head and neck cancer patients. J Laryngol Otol. 2006;120 (6):463-466. doi:10.1017/S0022215106000661

22. Raykher A, Russo L, Schattner M, et al. Enteral nutrition support of head and neck cancer patients. Nutr Clin Pract. 2007;22(1):68-73. doi:10.1177/011542650702200168

23. Hunter AMB. Nutrition management of patients with neoplastic disease of the head and neck treated with radiation therapy. Nutr Clin Pract. 1996;11(4):157-169. doi:10.1177/0115426596011004157

24. Murayama KM. Enteral feeding tube placement in head and neck cancer patients: special considerations. Nutr Clin Pract. 1997;12(1 Suppl):S34-S37. doi:10.1177/088453369701200112

25. Lee JH, Machtay M, Unger LD, et al. Prophylactic gastrostomy tubes in patients undergoing intensive irradiation for cancer of the head and neck. Arch Otolaryngol Head Neck Surg. 1998;124(8):871-875. doi:10.1001/archotol.124.8.871

26. Romesser PB, Romanyshyn JC, Schupak KD, et al. Percutaneous endoscopic gastrostomy in oropharyngeal cancer patients treated with intensity-modulated radiotherapy with concurrent chemotherapy. Cancer. 2012;118(24):6072-6078. doi:10.1002/cncr.27633

27. Hark MA. Grading of unintentional weight loss. Concise Manual Hematol Oncol. 1999.
28. Langmore S, Krisciunas GP, Miloro KV, et al. Does PEG use cause dysphagia in head and neck cancer patients? Dysphagia. 2012;27 (2):251-259. doi:10.1007/s00455-011-9360-2

29. Larson DE, Burton DD, Schroeder KW, et al. Percutaneous endoscopic gastrostomy. Indications, success, complications, and mortality in 314 consecutive patients. Gastroenterology. 1987;93(1):48-52. doi:10.1016/0016-5085(87)90312-X

30. Grant MD, Rudberg MA, Brody JA. Gastrostomy placement and mortality among hospitalized Medicare beneficiaries. JAMA. 1998;279(24):1973-1976. doi:10.1001/jama.279.24.1973

31. Chen AM, Li B-Q, Lau DH, et al. Evaluating the role of prophylactic gastrostomy tube placement prior to definitive chemoradiotherapy for head and neck cancer. Int J Radiat Oncol Biol Phys. 2010;78 (4):1026-1032. doi:10.1016/j.ijrobp.2009.09.036

32. Siddiqi AM, Hamilton RD, Minocha A. Malignant seeding of percutaneous endoscopic gastrostomy tract in patient with head and neck cancer. Am J Med Sci. 2008;336(3):291-292. doi:10.1097/MAJ.0b $013 \mathrm{e} 31815 \mathrm{~b} 60 \mathrm{ba}$

33. Arends J, Bachmann P, Baracos V, et al. ESPEN guidelines on nutrition in cancer patients. Clin Nutr. 2017;36:11-48. doi:10.1016/ j.clnu.2016.07.015

34. Takahashi M, Kosaka N, Wakui E, et al. Role of intensive nutrition support and prophylactic percutaneous endoscopic gastrostomy during concomitant chemoradiotherapy for oropharyngeal cancer. Int J Clin Oncol. 2018;23:1023. doi:10.1007/s10147-018-1328-x

\section{Publish your work in this journal}

Cancer Management and Research is an international, peer-reviewed open access journal focusing on cancer research and the optimal use of preventative and integrated treatment interventions to achieve improved outcomes, enhanced survival and quality of life for the cancer patient.
The manuscript management system is completely online and includes a very quick and fair peer-review system, which is all easy to use. Visit http://www.dovepress.com/testimonials.php to read real quotes from published authors. 